\title{
Impact of pandemic COVID-19 outbreak on oral mucositis preventive and treatment protocols: new perspectives for extraoral photobiomodulation therapy
}

\author{
Karina Morais Faria ${ }^{1}$ - Wagner Gomes-Silva ${ }^{1,2}$ • Elisa Kauark-Fontes ${ }^{3}$ - Carolina Guimarães Bonfim-Alves ${ }^{1,3}$. \\ Luiz Paulo Kowalski $^{4}$ - Ana Carolina Prado-Ribeiro ${ }^{1,3}$ - Aljomar José Vechiato-Filho ${ }^{1}$. Marcio Ajudarte Lopes ${ }^{3}$. \\ Gustavo Nader Marta ${ }^{5,6}$. Gilberto de Castro $\mathrm{Jr}^{7}$. Adriana Franco Paes Leme ${ }^{8}$. Cesar Augusto Migliorati ${ }^{9}$. \\ Alan Roger Santos-Silva ${ }^{3}$ (D) Thaís Bianca Brandão ${ }^{1}$
}

Received: 28 April 2020 / Accepted: 15 July 2020 / Published online: 21 July 2020

(C) Springer-Verlag GmbH Germany, part of Springer Nature 2020

\begin{abstract}
This communication discusses the current challenges of oral mucositis (OM) management during the pandemic COVID-19 outbreak and reflects about an extraoral photobiomodulation protocol as an optimal alternative for preventing and treating OM in advanced cancer patients while minimizing the risk of infection by avoiding intraoral manipulation.
\end{abstract}

Keywords COVID-19 · Oral mucositis · Cancer · Photobiomodulation therapy · Laser therapy

\section{Introduction}

The recent 2019 novel coronavirus disease (COVID-19) pandemic has dramatically changed several aspects of worldwide communities, evoking many changes in the routine activities of populations as well as impacting economic burden and functioning capacity of the healthcare system [1]. Since December 2019, when the first cases emerged in Wuhan (Hubei Province of China) [2,3], an exponential number of infected patients with the SARS coronavirus 2 (SARS-CoV2 ), the known etiologic agent of the COVID-19, has spread across multiple countries with rapid community dissipation of the virus $[4,5]$. Acute inflammatory distress syndrome is one

Alan Roger Santos-Silva

alanroger@fop.unicamp.br

1 Dental Oncology Service, Instituto do Câncer do Estado de São Paulo (ICESP), São Paulo, Brazil

2 Medical School, Nove de Julho University, UNINOVE, São Paulo, Brazil

3 Oral Diagnosis Department, Piracicaba Dental School, University of Campinas (UNICAMP), Piracicaba, Brazil

$4 \quad$ Head and Neck Surgery Department, University of Sao Paulo Medical School and Department of Head and Neck Surgery and Otorhinolaryngology A C Camargo Cancer Center, São Paulo, Brazil of the most life-threatening complications of COVID-19 and usually requires intensive care and mechanical ventilation [1], most frequently in more vulnerable patients, which include patients undergoing anticancer treatment or diagnosed with malignancies associated with an immunosuppressive state. Cumulative evidence suggests that cancer patients are at increased risk of COVID-19 infection [6], and early published reports estimated a significant higher risk of mortality over 3.5 times on cancer patients [7].

The person-to-person spread of COVID-19 disease seems to be rapid and may quickly overwhelm the care settings from primary to tertiary levels. In this scenario, oncologic care facilities have faced the dilemma of how to maintain cancer

5 Division of Radiation Oncology, Instituto do Câncer do Estado de São Paulo (ICESP), São Paulo, Brazil

6 Department of Radiation Oncology, Hospital Sírio-Libanês, São Paulo, Brazil

7 Department of Medical Oncology, Instituto do Câncer do Estado de São Paulo (ICESP), São Paulo, Brazil

8 Brazilian Biosciences National Laboratory, LNBio, CNPEM, Campinas, São Paulo, Brazil

9 College of Dentistry, University of Florida, Gainesville, Florida, USA 
treatment in the pandemic era, reaching appropriate treatment outcomes either for ongoing patient's therapies or therapies that will initiate during the growing phase of the outbreak, meanwhile promoting safety for both patients and healthcare professionals [8].

\section{Discussion}

Managing oral health before or during cancer treatment includes not only dental workup but also intraoral photobiomodulation therapy (PBMT)-validated protocols $[9$, $10]$ for prevention or treating oral mucositis (OM), which may place dentists and patients at a particularly high risk to COVID-19 transmission.

Therefore, it is paramount to rethink recommendations to oral care staff inserted in the oncologic setting with emphasis to PBMT protocols attempting to reduce risks of SARS-CoV2 transmission without restricting the markedly benefits of light-based protocols for OM management during radiation therapy and chemotherapy course [10]. In this sense, Professor Holden Thorp, the Editor-in-chief of Science, was very fortunate in saying that "The success of the world's scientists - along with strong political and social leadership will determine which scenarios unfold, so it is time to focus on what we can all do to help" [11]. Thus, our group reports herein the use of the so-called closed-mouth extraoral PBMT protocol based on the available body of evidence [12] of this approach against intraoral devices during the pandemic COVID-19 outbreak as an additional intention to control the contact with the saliva of potentially contaminated cancer patients.

This international challenging scenario brought new perspectives for our ongoing randomized controlled clinical trial [13] originally designed to characterize the impact of extraoral and intraoral PBMT protocols on OM and survival outcomes of patients with oral cavity and oropharynx squamous cell carcinoma. Due to the above-mentioned impact of pandemic COVID-19 outbreak on OM managing protocols, our group decided to focus exclusively on the PBMT delivery by using a large light-emitting diode (LED) probe. This technique permits the treatment within a reasonable time of tissues from an extraoral approach, enabling light delivery to the oral and oropharyngeal mucosa while avoiding intraoral manipulation as described by Treister et al. (2016) [12] and adapted for our clinical trial [13]. Moreover, it seems to be safe and effective to manage $\mathrm{OM}$ as well as associated pain with minimal discomfort for patients and less professional exposure to saliva [13-16].

We could eventually wait for several months to finish our ongoing trial [13] and publish more clear evidence about this strategy. However, since fast dissemination of COVID-19 viruses can be lethal to health professionals and global society, we decided to share such new insights with international supportive care in cancer multidisciplinary teams, in order to disseminate our transformed clinical practice to cope with COVID-19, as illustrated on Fig. 1.

The extraoral prophylactic and therapeutic PBMT parameters are based on a Class 2M LED Thor LX2 (Thor Photomedicine Ltd., Chesham, London, UK) operating with a 69 diode LED cluster probe $(1390 \mathrm{~mW})$. The probe contains $34 \times 6060$-nm LED with the following specifications: 6060$\mathrm{nm}$ central wavelength; spectral width of $20 \mathrm{~nm}$ at $50 \%$ intensity, average power of $10 \mathrm{~mW}$, active area of $0.2 \mathrm{~cm}^{2}$; power density (irradiance) of $51 \mathrm{~mW} / \mathrm{cm}^{2}$; and beam divergence of $20^{\circ}$ half angle associated with $35 \times 850$-nm LED with the following specifications, 850 -nm wavelength; spectral width of $45 \mathrm{~nm}$ at $50 \%$ intensity, average power of $30 \mathrm{~mW}$, active area of $0.2 \mathrm{~cm}^{2}$; power density (irradiance) of $150 \mathrm{~mW} / \mathrm{cm}^{2}$; and beam divergence of $22^{\circ}$ half angle leading to $1390 \mathrm{~mW}$ of total power, an outer diameter probe of $70 \mathrm{~mm}, 63 \mathrm{~mm}$ of diameter of active area, and an average power density of $44.6 \mathrm{~mW} / \mathrm{cm}^{2}$ [12].

The LED device is being applied flat against the face and neck of the patients (Fig. 2) at five treatment sites: face (right, center and left sides) and neck (right and left sides) [13]. The device is applied for $60 \mathrm{~s}$ per location $(50 \mathrm{~mW} / \mathrm{cm} 2 \times 60 \mathrm{~s}=$ $3.0 \mathrm{~J} / \mathrm{cm} 2$ for five locations) [12]. No safety goggles are required for the patients because it is a LED probe, which in the current context may also avoid cross contamination among patients.

Despite the use of the closed-mouth extraoral PBMT technique, a systematic disinfectant routine of the equipment and work environment is indispensable. This includes the disinfection of all surfaces in patient-care areas and PBMT probes/ equipment with hospital standardized disinfectants, such as $70 \%$ ethylic alcohol and quaternary ammonium compounds [17]. After disinfection, the probe is protected with plastic film before clinical use and is immediately disposed after the procedure. Proper COVID-19 professional protective equipment use (disposable working cap, disposable doctor cap, goggles or face shield, disposable surgical mask, and disposable gloves, among others) must be consistent with the World Health Organization protocols designed for health workers [17], local institutional guidelines, and also with the regional government recommendations.

The use of extraoral PBMT for oral mucositis is not fully novel; however, current treatment protocols often focus on intraoral PBMT. Hence, considering the current situation with COVID-19, we believe our experience may guide novel treatment protocols to protect cancer patients and providers. The main limitation of this report is that it does not support with details the grade of the OM outcomes or the results of the treatment due to the fact that an interim analysis of clinical data would take several weeks to be collected in the current panorama of the pandemic. 


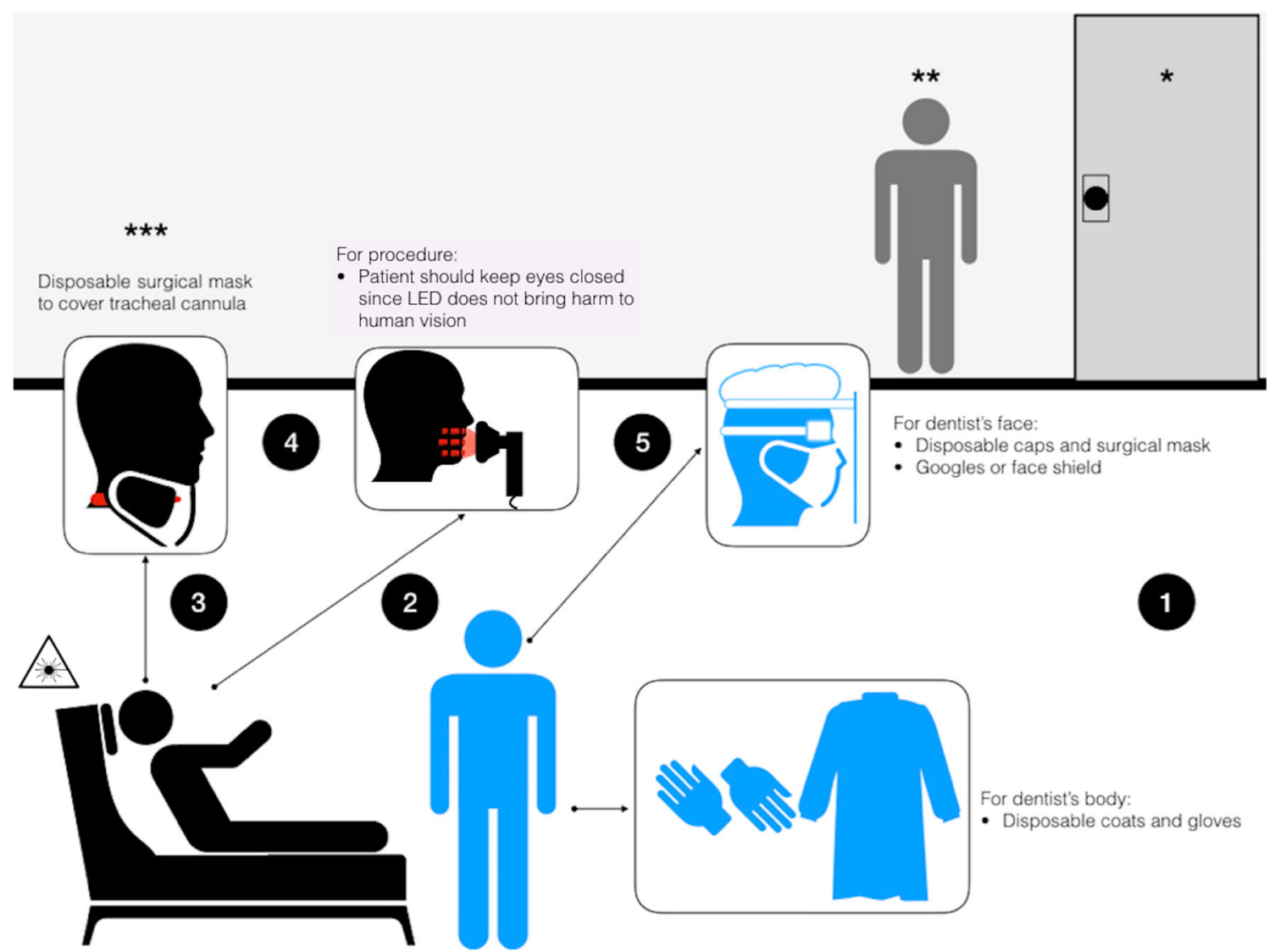

Fig. 1 Scheme summarizing all information necessary for a safe PBMT appointment. *Door of the hospital room should be closed with lowpressure inside in cases of COVID-19 suspicion or confirmation, or the door or window should be opened to provide airflow, minding to not put other individuals in risk of infection.** Patient's family member or carer should wait outside the hospital room. *** Patients with advanced tumors may be subjected to neck dissection with protective tracheostomy in complementation to solid tumor removal-especially for those individuals with adjuvant or exclusive radiotherapy. Cough and secretive fluids are common and persistent during radiation treatment,

representing an important infection source. Therefore, their tracheal cannula should be covered with a disposable surgical mask. Also important, professionals should sanitize their hands with water and soup or alcohol gel (1) before patient examination, (2) before dental procedures, (3) after touching the patient, (4) after touching equipment without disinfection, and (5) after touching the oral mucosa or body fluids. Laser flag was positioned in the back of the patient because we suggest that professionals keep PBM equipment behind working chair to avoid contamination in case of infected droplets

\section{Conclusion}

The pandemic COVID-19 outbreak brought new perspectives for the development of extraoral PBMT protocols designed to reduce risks of SARS-CoV-2 transmission without limiting its

benefits on OM management during radiotherapy and chemotherapy for advanced cancer patients.

Acknowledgments The authors would like to gratefully acknowledge the financial support of the São Paulo Research Foundation (FAPESP) processes numbers 2018/02233-6 and 2018/23479-3.
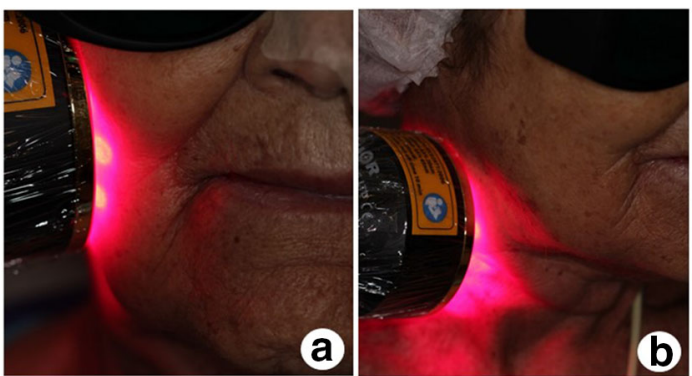

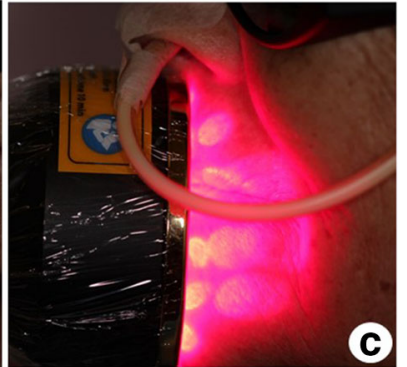

images, PBMT should be applied at the right side of the face (a), right side of the neck (b), center face (c), and then repeated for the left side of the patient's face and neck
Fig. 2 Extraoral PBMT protocol with 69 diodes LED cluster probe $(1390 \mathrm{~mW})$ being applied for the prevention of chemoradiation-induced oral mucositis in an oral squamous cell patient. As demonstrated in these 
Funding information São Paulo Research Foundation (FAPESP, Brazil) sponsors the entire clinical research protocol described herein including the achievement of equipment and consumables. Alan Roger SantosSilva is a research grantee of The Brazilian National Council for Scientific and Technological Development (CNPq, Brazil).

\section{Compliance with ethical standards}

Conflict of interest The authors declare that they have no conflict of interest.

Control of the data The authors have full control of all primary data and agree to allow the journal to review our data if requested.

\section{References}

1. Zhu N, Zhang D, Wang W, Li X, Yang B, Song J, Zhao X, Huang B, Shi W, Lu R, Niu P, Zhan F, Ma X, Wang D, Xu W, Wu G, Gao GF, Tan W, China Novel Coronavirus Investigating and Research Team (2020) A novel coronavirus from patients with pneumonia in China, 2019. N Engl J Med 382(8):727-733. https://doi.org/10. 1056/NEJMoa2001017

2. Li Q, Guan X, Wu P, Wang X, Zhou L, Tong Y, Ren R, Leung KSM, Lau EHY, Wong JY, Xing X, Xiang N, Wu Y, Li C, Chen Q, Li D, Liu T, Zhao J, Liu M, Tu W, Chen C, Jin L, Yang R, Wang Q, Zhou S, Wang R, Liu H, Luo Y, Liu Y, Shao G, Li H, Tao Z, Yang Y, Deng Z, Liu B, Ma Z, Zhang Y, Shi G, Lam TTY, Wu JT, Gao GF, Cowling BJ, Yang B, Leung GM, Feng Z (2020) Early transmission dynamics in Wuhan, China, of novel coronavirus-infected pneumonia. N Engl J Med 382(13):1199-1207. https://doi.org/10. 1056/NEJMoa2001316

3. Holshue ML, DeBolt C, Lindquist S, Lofy KH, Wiesman J, Bruce H, Spitters C, Ericson K, Wilkerson S, Tural A, Diaz G, Cohn A, Fox L, Patel A, Gerber SI, Kim L, Tong S, Lu X, Lindstrom S, Pallansch MA, Weldon WC, Biggs HM, Uyeki TM, Pillai SK, Washington State 2019-nCoV Case Investigation Team (2020) First case of 2019 novel coronavirus in the United States. N Engl J Med 382(10):929-936. https://doi.org/10.1056/NEJMoa2001191

4. Phan LT, Nguyen TV, Luong QC, Nguyen TV, Nguyen HT, Le HQ, Nguyen TT, Cao TM, Pham QD (2020) Importation and human-to-human transmission of a novel coronavirus in Vietnam. N Engl J Med 382(9):872-874. https://doi.org/10.1056/ NEJMc2001272

5. Wu Z, McGoogan JM (2020) Characteristics of and important lessons from the coronavirus disease 2019 (COVID-19) outbreak in China: summary of a report of 72314 cases from the Chinese Center for Disease Control and Prevention. JAMA. 323(13):1239-1242. https://doi.org/10.1001/jama.2020.2648

6. Yu J, Ouyang W, Chua MLK, Xie C (2020) SARS-CoV-2 transmission in patients with cancer at a Tertiary Care Hospital in Wuhan, China. JAMA Oncol. https://doi.org/10.1001/jamaoncol. 2020.0980

7. Liang W, Guan W, Chen R, Wang W, Li J, Xu K, Li C, Ai Q, Lu W, Liang H, Li S, He J (2020) Cancer patients in SARS-CoV-2 infection: a nationwide analysis in China. Lancet Oncol 21(3):335337. https://doi.org/10.1016/S1470-2045(20)30096-6

8. Al-Shamsi HO, Alhazzani W, Alhuraiji A, Coomes EA, Chemaly RF, Almuhanna M, Wolff R, Nuhad IK, Chua MLK, Hotte SJ, Meyers BM, Elfiki T, Curigliano G, Eng C, Grothey A, Xie C
(2020) A practical approach to the management of cancer patients during the novel coronavirus disease 2019 (COVID-19) pandemic: an international collaborative group. Oncologist. https://doi.org/10. 1634/theoncologist.2020-0213

9. Brandão TB, Morais-Faria K, Ribeiro ACP, Rivera C, Salvajoli JV, Lopes MA, Epstein JB, Arany PR, de Castro G Jr, Migliorati CA, Santos-Silva AR (2018) Locally advanced oral squamous cell carcinoma patients treated with photobiomodulation for prevention of oral mucositis: retrospective outcomes and safety analyses. Support Care Cancer 26(7):2417-2423. https://doi.org/10.1007/s00520018-4046-Z

10. Zadik Y, Arany PR, Fregnani ER, Bossi P, Antunes HS, Bensadoun RJ, Gueiros LA, Majorana A, Nair RG, Ranna V, Tissing WJE, Vaddi A, Lubart R, Migliorati CA, Lalla RV, Cheng KKF, Elad S, Mucositis Study Group of the Multinational Association of Supportive Care in Cancer/International Society of Oral Oncology (MASCC/ISOO) (2019) Systematic review of photobiomodulation for the management of oral mucositis in cancer patients and clinical practice guidelines. Support Care Cancer 27(10):3969-3983. https://doi.org/10.1007/s00520-019-04890-2

11. Thorp HH (2020) Time to pull together. Science 367(6484): 1282. https://doi.org/10.1126/science.abb7518

12. Treister NS, London WB, Guo D, Malsch M, Verrill K, Brewer J, Margossian S, Duncan C (2016) A feasibility study evaluating extraoral photobiomodulation therapy for prevention of mucositis in pediatric hematopoietic cell transplantation. Photomed Laser Surg 34(4):178-184. https://doi.org/10.1089/pho.2015.4021

13. Oncological safety of intraoral and extraoral photobiomodulation in patients with oral and oropharyngeal squamous cell carcinoma. Ensaiosclinicos.gov. https://apps.who.int/trialsearch/Trial2.aspx? TrialID=RBR-4w4swx. Accessed 13 April 2020

14. Arora H, Pai KM, Maiya A, Vidyasagar MS, Rajeev A (2008) Efficacy of He-Ne Laser in the prevention and treatment of radiotherapy-induced oral mucositis in oral cancer patients. Oral Surg Oral Med Oral Pathol Oral Radiol Endod 105(2):180-186, 186.e1. https://doi.org/10.1016/j.tripleo.2007.07.043

15. Hodgson BD, Margolis DM, Salzman DE, Eastwood D, Tarima S, Williams LD, Sande JE, Vaughan WP, Whelan HT (2012) Amelioration of oral mucositis pain by NASA near-infrared lightemitting diodes in bone marrow transplant patients. Support Care Cancer 20(7):1405-1415. https://doi.org/10.1007/s00520-0111223-8

16. Zecha JA, Raber-Durlacher JE, Nair RG, Epstein JB, Sonis ST, Elad S, Hamblin MR, Barasch A, Migliorati CA, Milstein DM, Genot MT, Lansaat L, van der Brink R, Arnabat-Dominguez J, van der Molen L, Jacobi I, van Diessen J, de Lange J, Smeele LE, Schubert MM, Bensadoun RJ (2016) Low level laser therapy/ photobiomodulation in the management of side effects of chemoradiation therapy in head and neck cancer: part 1: mechanisms of action, dosimetric, and safety considerations. Support Care Cancer 24(6):2781-2792. https://doi.org/10.1007/s00520-016-3152-z

17. World Health Organization (WHO). Infection prevention and control during healthcare when COVID-19 is suspected. Interim guidance, 2020. https://www.who.int/publications-detail/infectionprevention-and-control-during-health-care-when-novelcoronavirus-(ncov)-infection-is-suspected-20200125/. Accessed on April $9^{\text {th }}, 2020$

Publisher's note Springer Nature remains neutral with regard to jurisdictional claims in published maps and institutional affiliations. 